\title{
IMMUNE RESPONSES TO KILLED REASSORTED INFLUENZA VIRUS SUPPLEMENTED WITH NATURAL ADJUVANTS
}

\author{
Mona Abdel Fattah Razin ${ }^{1}$, Ahmed Osman ${ }^{2}$, Mohamed Ahmed Ali $^{3}$, \\ MAHMOUD MOHAMED BAHGAT ${ }^{4} *$ and AMANY SAYED MAGHRABY ${ }^{4}$ \\ ${ }^{1}$ Therapeutic Chemistry Department, Pharmaceutical and Drug Industries Research \\ Division, National Research Centre, Giza, Egypt \\ ${ }^{2}$ Department of Biochemistry, Faculty of Science, Ain Shams University, Cairo, Egypt \\ ${ }^{3}$ The Center of Excellence for Influenza Research, National Research Centre, Giza, Egypt \\ ${ }^{4}$ Research Group Immune- and Bio-markers for Infection, the Center of Excellence for \\ Advanced Sciences and Therapeutic Chemistry Department, Pharmaceutical and Drug \\ Industries Research Division, National Research Centre, Giza, Egypt
}

(Received: 31 May 2016; accepted: 22 March 2017)

In this study, we investigated the immunomodulatory effects of a supplemented killed influenza virus (V) by Echinacea purpurea (E) and Nigella sativa $(\mathrm{N})$ extracts and effect of changing the route of immunization from intramuscular (IM) to intraperitoneal (IP). At the $2^{\text {nd }}-, 3^{\text {rd }}$ - and $4^{\text {th }}$-week post-IM immunizations (WPIMI), the supplemented $\mathrm{V}$ with $\mathrm{N}(\mathrm{VN})$ induced the most significant $\mathrm{IgM}$ response unlike $\mathrm{N}$ alone. At the $2^{\text {nd }}$ WPIMI, V or VN induced the highest significant IgG levels. At the $2^{\text {nd }}$-week post-IP immunization (WPIPI), E and VN induced the most significant IgG levels. Both at the $3^{\text {rd }}$ and $4^{\text {th }}$ WPIMI or WPIPI, various treatments induced significant increases in IgG. At the $4^{\text {th }}$ WPIMI, E, V, and V with $\mathrm{E}$ (VE) induced significant increases in the CD4+ thymocytes while all IP treatments caused significant increase in their counts. $\mathrm{V}$ and $\mathrm{VN}$ induced the most significant IM induction of CD8+ thymocytes while their best IP stimulation was induced by N, VE, and VN. At the $4^{\text {th }}$ WPIMI, various treatments caused significant increases in the mesenteric lymph node (MLN) CD4+, CD8+ counts. WPIPI with V or VE caused significant increases in both the CD4+- and CD8+ MLN cells, whereas VN significantly induced CD8+ MLN cells only. WPIPI with various treatments caused significant increases in the B-cell counts and the peak was obtained by $\mathrm{VN}$.

Keywords: avian influenza, reassortment, Echinacea purpurea, Nigella sativa, immunoglobulins, lymphocytes

*Corresponding author; E-mails: mbahgatriad@yahoo.com; mm.riad@nrc.sci.eg 


\section{Introduction}

Influenza viruses fall among extensively studied pathogens, yet available control measures still require continuous improvement and updating to enable facing continuous challenges by emerging pandemics. Antiflu vaccines come on the top of the list of control measures which require frequent modification and updating due to continuous antigenic drift and sporadic antigenic shifts in the viral surface glycoproteins reviewed by Webster and Govorkova [1].

Hemagglutinin (HA) represents the most immunogenic influenza surface antigen, which determines host immune responses to the infections [2, 3]. Mutations which take place in the HA affect the immune response, therefore, annual updating of the HA molecule included in the used anti-influenza vaccines is essential to ensure their efficacy [4]. Relying on vaccines which were tailored based on antigenically distantly related influenza strains to any of the highly pathogenic avian influenza (HPAI) H5N1 clades may be among the reasons for the poor immunological and protective capacity of such vaccines and this was clearly seen in Egypt upon using the commercial vaccine Volvac which is based on the $\mathrm{A} / \mathrm{Ck} / \mathrm{Mexico} / 232 / 94$ (H5N2) virus [5].

Another major influenza glycoprotein for viral classification, infectivity, and pathogenesis is the neuraminidase (NA) which represents the major target for discovery of anti-influenza drug as it cleaves neuraminic (sialic) acid to which new virions are bound and thus facilitates their exocytosis from host cells [6-8]. Thus, emerging mutations in sequences of NA from new influenza pandemics would change response to NA inhibitors and might result in resistance to therapy [9].

In addition to immunogenic viral antigens, adjuvants play major role in the immunological outcome to a given vaccine [10]. As examples for the used adjuvants in commercial anti-influenza vaccines, Advax ${ }^{\mathrm{TM}}$ is a polysaccharide based on delta inulin [11], MF59 is an oil-in-water emulsion [12] and phosphatidylcholine bilayer liposomes in which viral NA and HA embedded a formula known as virosomal adjuvanted influenza vaccine which has the commercial name Inflexal $^{\circledR} \mathrm{V}$ reviewed by Herzog et al. [13].

Due to its highly pathogenic nature, the immune responses to both HA and NA of avian influenza isolates which caused outbreaks in Egypt were not studied. Also the capacity of various adjuvants and routes of administration to modify the immunological outcomes of vaccines based on local Egyptian strains were not addressed.

Therefore, here we generated a reassorted virus presenting the HA5 and NA1 of a HPAI virus on a low pathogenic PR8-H1N1 background by reverse 
genetics [14] and used its killed form to immunize mice. In addition, we supplemented killed virus with extracts of two plants to investigate their immunomodulatory value upon changing routes of immunization. The used extracts from Echinacea purpurea $(\mathrm{E})$ and Nigella sativa $(\mathrm{N})$ were previously reported for their immunomodulatory effects [15-18].

The ultimate goals of the work were to dissect the influenza-specific cellular and humoral responses and the adjuvant-induced non-specific responses elicited in mice treated with the killed reassorted virus supplemented by these natural extracts and to identify the route of immunization that mediates the best immunological outcome.

\section{Materials and Methods}

Propagation of virus

The killed reassorted virus was generated by reverse genetics ( $\mathrm{rg}$ ) of $\mathrm{HA}$ of a highly pathogenic avian H5N1 influenza isolate from Egypt on PR8-H1N1 background. The virus seed used to prepare the vaccine strain $\mathrm{rg}[\mathrm{A} / \mathrm{chicken} /$ Egypt/Q1995D/2010 (H5N1)], which was propagated in Madin-Darby canine kidney (MDCK) cells and titrated by the plaque infectivity assay as previously reported by Hoffmann et al. [14].

\section{Preparation of the vaccine}

The rg Q1995 virus [A/chicken/Egypt/Q1995D/2010 (H5N1)] was propagated in pathogen-free embryonated chicken eggs (SPF-ECE; Nil S.P.F., Fayoum, Egypt). The virus particles were chemically inactivated by mixing the allantoic fluid with $\beta$-propiolactone. Complete inactivation of any infectious viral particles was further confirmed by co-incubating the $\beta$-propiolactone-treated allantoic fluid with MDCK cells and excluding emergence of any cytopathic effects microscopically for $72 \mathrm{~h}$.

\section{Adjuvant from plant origin}

An amount of $3.5 \mathrm{mg} / 100 \mu \mathrm{l}$ phosphate-buffered saline (PBS) from the pressed juice of E-dried powder (Sekem Erosp Co., Cairo, Egypt) was prepared according to the method of Mishima et al. [16]. An amount of $20 \mu \mathrm{l}$ from $\mathrm{N}$ oil 
(Sekem Erosp Co.) was completed to $100 \mu \mathrm{l}$ by PBS according to the published method by Assayed [19].

Formulation of the inactivated virus vaccines with the adjuvants from plant origin

E-dried powder $(3.5 \mathrm{mg} / 100 \mu \mathrm{l} \mathrm{PBS})$ was mixed with the vaccine and homogenized for $10 \mathrm{~min}$ at room temperature (RT). The resulting formulation from mixing $\mathrm{V}$ with $\mathrm{E}$ was called $\mathrm{VE}$. $\mathrm{N}$ oil was mixed with the vaccine at a concentration of $20 \%(2 \mathrm{ml} \mathrm{N}$ oil $+8 \mathrm{ml} \mathrm{rH} 5 \mathrm{~N} 12010)$. The vaccine and $\mathrm{N}$ oil were mixed well by homogenizer for $10 \mathrm{~min}$ at RT [V with $\mathrm{N}(\mathrm{VN})$ ]. The used dose of VN was $100 \mu \mathrm{l} / \mathrm{mouse}$.

\section{Immunization protocols}

Sixty female Swiss albino mice weighing 15-27 g were used for the study. The number of control (C) and immunized mice by E, N, V, VE, or VN per each group was 5. Animals were fed on a standard diet and maintained at ambient temperature according to the animal welfare protocols of the National Research Centre (NRC) in Egypt. Anesthesia procedures complied with the guidelines of the National Institutes of Health in the USA and were approved by the Medical Ethical Committee of the NRC (registration number: 11032).

Individual mice groups received either intraperitoneal immunization (IPI) or intramuscular immunizations (IMI) with, E, N oil, the inactivated vaccine containing no adjuvant (V), or with the abovementioned plants (VE and VN). The last group kept as naïve (C).

\section{Separation of sera and collection of lymphoid organs}

Blood samples were collected from optical plexus of individual mice at $1^{\text {st }}$ and $2^{\text {nd }}$-week post-priming and boosting. Sera were separated by centrifugation at $10,000 \mathrm{~g}$, divided into multiple aliquots, and frozen at $-80^{\circ} \mathrm{C}$ till being used. After 2-week post-boosting animals were sacrificed, lymphoid organs [mesenteric lymph nodes (MLNs) and thymus] were dissected and used for immunophenotyping analysis.

Detection of IgM and IgG levels in sera from immunized and control mice by ELISA

Assays were carried out as previously described by Bahgat et al. [20]. Plates were coated with $50 \mu \mathrm{l} /$ well inactivated appropriately diluted virus antigen and 
blocked using $100 \mu \mathrm{l} /$ well of PBS with Tween 20 containing 5\% fetal calf serum (PBST-FCS). Diluted sera in PBST-FCS were applied $50 \mu 1 /$ well and plates were incubated at $37{ }^{\circ} \mathrm{C}$ for $2 \mathrm{~h}$. To detect total IgM and IgG, diluted peroxidaseconjugated anti-mouse IgM and IgG (KPL, Gaithersburg, MD, USA) in PBSTFCS were added $(50 \mu 1 /$ well). To develop the reaction, the colorimetric substrate $O$-phenylenediamine (Sigma, St. Louis, MO, USA) was used in presence of $\mathrm{H}_{2} \mathrm{O}_{2}$ and the enzymatic reaction was stopped using $2 \mathrm{M} \mathrm{HCl}$. The changes in optical densities were recorded at $\lambda_{\max } 490 \mathrm{~nm}$ using a multi-well plate reader (Sunrise, Tecan Austria GmbH, Grödig, Austria).

\section{Immunophenotyping analysis of different lymphocytes populations}

Immunophenotypic staining of different lymphocytes was done according to Maghraby and Bahgat [21]. MLN and thymus were excised, gently teased in Petri dishes containing PBST-FCS using glass slides. Pooled cells were washed three times with PBST-FCS by centrifugation at $1,500 \mathrm{~g}$ and $4{ }^{\circ} \mathrm{C}$ for $10 \mathrm{~min}$. CD4+, CD8+ T- and B-lymphocytes were labeled with FITC-conjugated monoclonal antibodies obtained from Biolegend (San Diego, CA, USA) and KPL, respectively. To calculate the mean percentage of each cell population, green fluorescence stained cells were counted in a minimum of 100 viable pooled cells using a fluorescence microscope (Zeiss Axioskop, Jena, Germany).

\section{Statistical analysis}

Statistical analysis and plots were performed using the GraphPad PRISM version 5 software. The results were expressed as mean \pm standard deviation (SD). Means, SDs, and degree of significance were calculated using the unpaired data comparison application of the Student's $t$-test included in the software. Differences were considered significant when $P$ values were $<0.05$. The number of asterisks represents the degree of significance where ${ }^{*}$ means $P<0.05$, ** means $P<0.005$, and $* * *$ means $P<0.0005$, whereas "ns" means not significant.

\section{Results}

Humoral immune responses

Kinetics and effect of route of immunization on the IgM response. At the $1^{\text {st }}$ week post-immunization except for mice which received the VN intramuscularly, 
all other immunized mouse groups through the IM route (Figure 1A) or IP route (Figure 1B) showed significantly higher IgM levels than control mice. At $1^{\text {st }}$-week post-IM immunization (WPIMI) or $1^{\text {st }}$-week post-IP immunization (WPIPI), the highest IgM levels were recorded in the treated mice with $\mathrm{E}$ alone which was significantly higher than in the rest of mouse groups.

At the $2^{\text {nd }}$ WPIMI (Figure 1C), except for mice which received the $\mathrm{N}$ alone, all immunized mice showed significantly higher IgM levels than control mice. Although mice which received the supplemented vaccine with the $\mathrm{N}(\mathrm{VN})$ showed the highest levels of $\operatorname{IgM}$, differences were ns compared with other various immunized mouse groups (Figure 1C). At the $2^{\text {nd }}$ WPIPI, all treated animals showed significantly higher levels of IgM compared with control mice (Figure 1D).

The highest IgM levels were detected in sera from treated mice with V and levels were significantly higher than in mouse groups which received other treatments except for those who received E (Figure 1D). At the $3^{\text {rd }}$ WPIMI or WPIPI, mice which received various treatments showed uniformly significantly higher IgM levels compared with control animals (Figure 1E and 1F). In the IM groups, peak IgM levels were seen in the mice which received the VN which were significantly higher than in the rest of the groups except for mice which received the un-supplemented V (Figure 1E).

In the IP groups, the peak levels were seen in sera from immunized mice with the un-supplemented $\mathrm{V}$ which were significantly higher than in the rest of the groups except for mice which received the supplemented vaccine with $\mathrm{N}$ (Figure $1 \mathrm{~F}$ ). At the $4^{\text {th }}$ WPIMI, unlike other treatments neither $\mathrm{E}$ nor $\mathrm{N}$ induced any significant changes in the IgM levels compared with control mice and the peak IgM level was obtained in mice which received the supplemented vaccine with $\mathrm{N}$ which were significantly higher than all other groups (Figure $1 \mathrm{G}$ ).

While, except for IP immunization with $\mathrm{N}$, various other IP immunizations resulted in significant elevations in the IgM levels and the peak levels were obtained in mice which received the un-supplemented vaccine which were significantly higher than all other groups (Figure $1 \mathrm{H}$ ). Interestingly, at $2^{\text {nd }}, 3^{\text {rd }}$ and $4^{\text {th }}$ WPIMI, although $\mathrm{N}$ alone did not induce high IgM responses, supplementing the vaccine with $\mathrm{N}$ induced the best IgM response compared with all other groups. Also, it was obvious that the best IgM response in case of both routes of immunizations at the earliest time point was induced by E alone and this was later inverted in all later time points. Of note, the outcome of the IM immunization was always better than the IP route.

Kinetics and effect of route of immunization on the $\operatorname{Ig} G$ response. At the $1^{\text {st }}$ WPIMI or WPIPI (Figure 2A and 2B), various treatments caused significant 

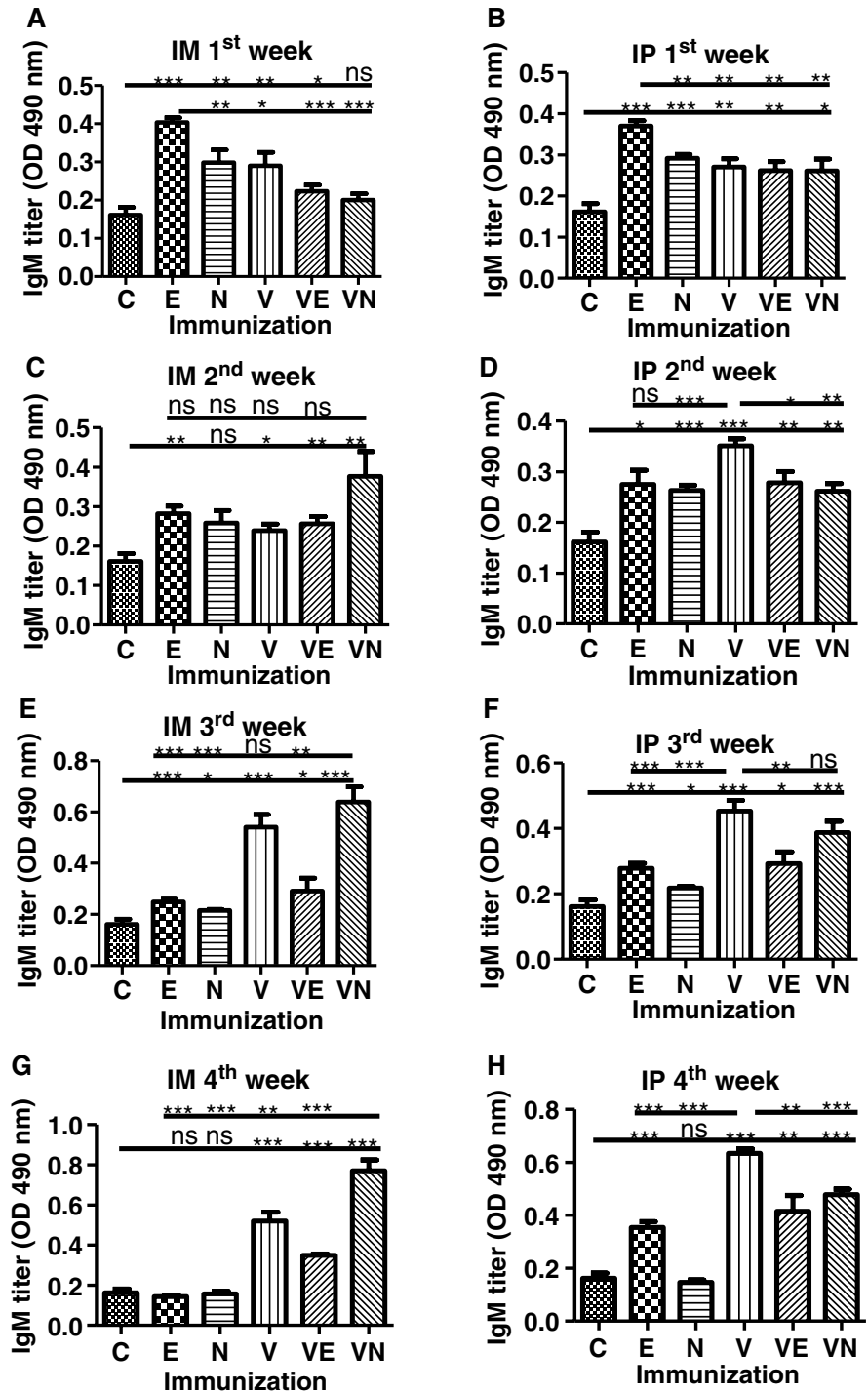

Figure 1. Detection of IgM levels in sera from mice immunized by anti-HPAI vaccine (V) preparation supplementing with Echinacea purpurea (E) and Nigella sativa (N) via two routes of immunizations, i.e., intramuscular (IMI) or intraperitoneal (IPI). A: $1^{\text {st }}$ week of IMI. B: $1^{\text {st }}$ week of IPI. C: $2^{\text {nd }}$ week of IMI. D: $2^{\text {nd }}$ week of IPI. E: $3^{\text {rd }}$ week of IMI. F: $3^{\text {rd }}$ week of IPI. G: $4^{\text {th }}$ week of IMI. H: $4^{\text {th }}$ week of IPI. The number of control and immunized mice per each group was 5 . Differences were considered significant when $P$ values were $<0.05$. The number of asterisks represents the degree of significance. ${ }^{*} P<0.05$, $* * P<0.005$, and ${ }^{* * *} P<0.0005$. ns: not significant 
A

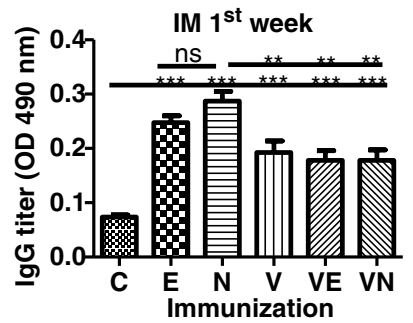

C
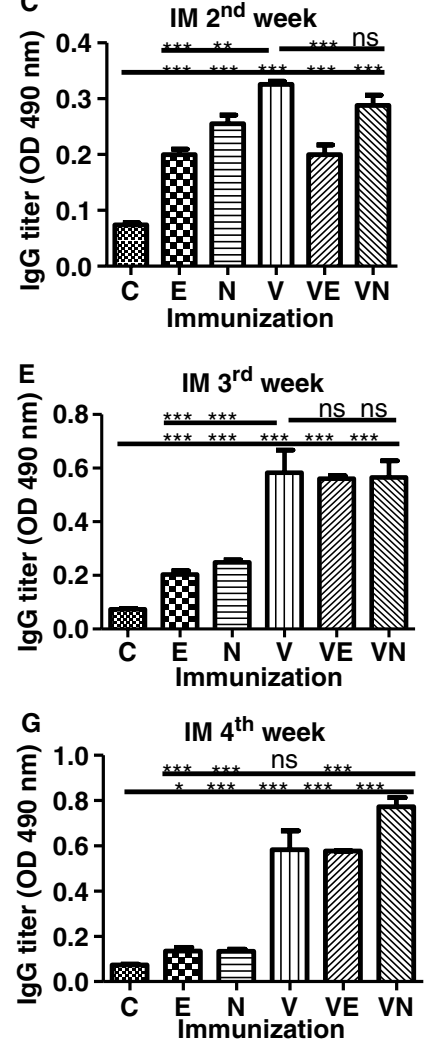
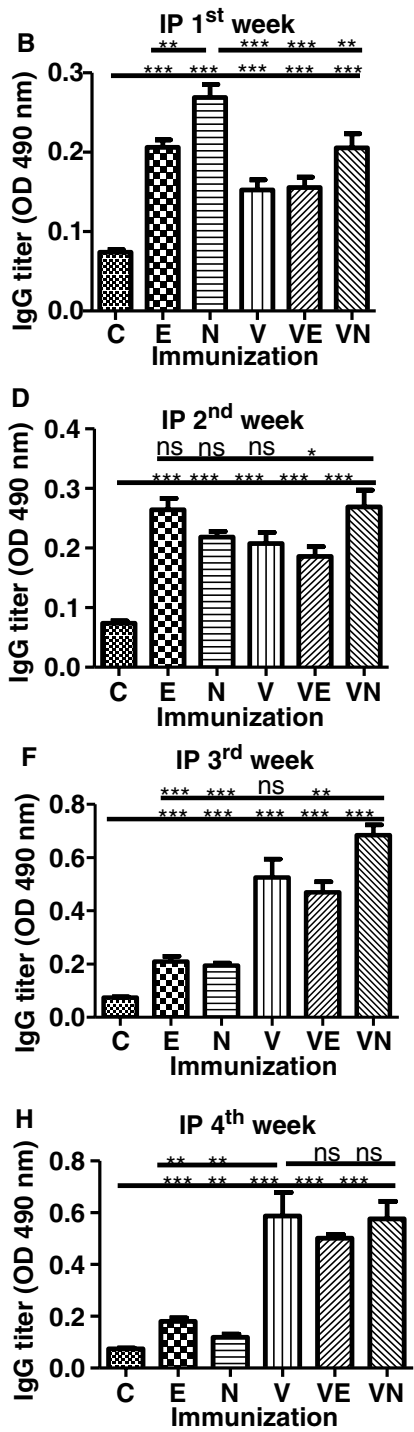

Figure 2. Detection of IgG levels in sera from mice immunized by anti-HPAI vaccine $(\mathrm{V})$ preparation supplementing with Echinacea purpurea $(\mathrm{E})$ and Nigella sativa $(\mathrm{N})$ via two routes of immunizations, i.e., intramuscular (IMI) or intraperitoneal (IPI). A: $1^{\text {st }}$ week of IMI. B: $1^{\text {st }}$ week of IPI. C: $2^{\text {nd }}$ week of IMI. D: $2^{\text {nd }}$ week of IPI. E: $3^{\text {rd }}$ week of IMI. F: $3^{\text {rd }}$ week of IPI. G: $4^{\text {th }}$ week of IMI. H: $4^{\text {th }}$ week of IPI. The number of control and immunized mice per each group was 5 . Differences were considered significant when $P$ values were $<0.05$. The number of asterisks represents the degree of significance. ${ }^{*} P<0.05,{ }^{*} P<0.005$, and ${ }^{* * *} P<0.0005$. ns: not significant 
increases in the IgG levels compared with levels in control animals and the most significant increases were observed in the case of immunizations with $\mathrm{N}$ followed by E. In case of the IP immunization (Figure 2B), supplementing the vaccine with $\mathrm{N}$ resulted in a significant induction of $\mathrm{IgG}$ compared with the induced $\mathrm{IgG}$ response with the $\mathrm{V}$ alone suggesting an immune stimulatory effect of the $\mathrm{N}$.

At the $2^{\text {nd }}$-week post-immunization via the two routes (Figure $2 \mathrm{C}$ and $2 \mathrm{D}$ ), all treatments uniformly caused significant increases in the $\mathrm{IgG}$ response. In case of the IM immunization (Figure 2C), the highest IgG levels were obtained upon treatment with $\mathrm{V}$ or $\mathrm{VN}$, whereas the least $\mathrm{IgG}$ induction was obtained upon treating mice with E or VE. Unlikely, in case of the IP immunization (Figure 2D), the highest IgG levels were obtained upon treatment with $\mathrm{E}$ and $\mathrm{VN}$. The distinct differences in the trend of the IgG responses between the IP (Figure 2D) and the IM immunizations (Figure 2C) suggest immunization route-specific immune response.

Both at the $3^{\text {rd }}$ - and $4^{\text {th }}$-week post-immunization via the two immunization routes (Figure $2 \mathrm{E}-2 \mathrm{H}$ ), various treatments differentially induced significant increases in the $\operatorname{IgG}$ response compared with control levels and the most significant increases were shown upon treatment with $\mathrm{VN}, \mathrm{V}$, and VE.

\section{Cellular immune responses}

Thymus cells (Figure 3). At the $4^{\text {th }}$ WPIMI (Figure 3A), the CD4+ thymocytes showed significant increases only upon treatment with the $\mathrm{E}$, the $\mathrm{V}$, and the VE with the highest mean percentage recorded in case of VE. Whereas IP immunization clearly induced better induction of CD4+ thymocytes compared with the IM route as various IP treatments (Figure 3B) caused highly significant increase in the mean percentage of such cell population compared with control levels. As for CD8+ cells, the most significant IM induction (Figure 3C) was obtained by the $\mathrm{V}$ and the $\mathrm{VN}$, whereas the best IP stimulation was induced by the $\mathrm{N}$, the VE, and the VN (Figure 3D).

Mesenteric lymph node cells. At the $4^{\text {th }}$ WPIMI, various treatments caused significant increases (Figure 4A and $4 \mathrm{C}$ ) in the mean percentage CD4+ and CD8+ cells compared with the control level. As for the IP immunizations, V and VE caused significant increases in the CD4+ cells (Figure 4B), whereas V, VE, and VN, caused significant increases in the CD8+ cells (Figure 4D). Notably, IM with $\mathrm{N}$ alone caused significant decrease in the mean percentage CD4+ counts compared with the control levels (Figure 4A). At the $4^{\text {th }}$-week post-immunization via the two routes, various treatments caused significant increases in the mean percentages of the $\mathrm{B}$ cells compared with the control levels and the most 

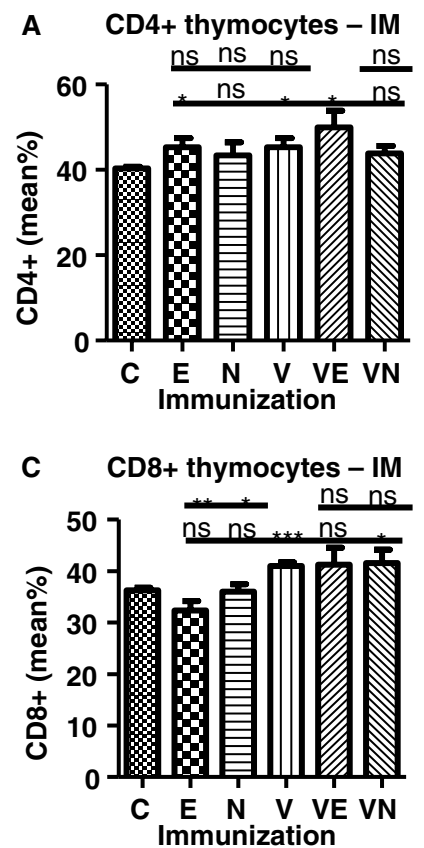
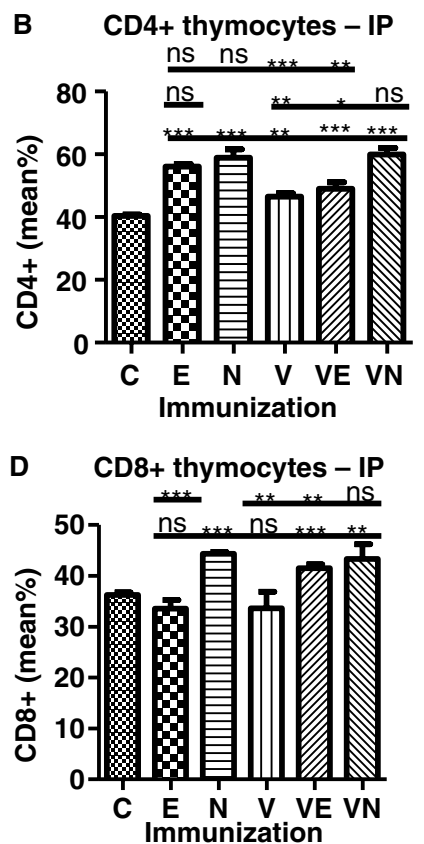

Figure 3. Mean percentage of CD4+ and CD8+ thymocytes at $4^{\text {th }}$ week of immunization from mice immunized by anti-HPAI vaccine (V) preparation supplementing with Echinacea purpurea (E) and Nigella sativa $(\mathrm{N})$ via two routes of immunizations, i.e., intramuscular (IMI) or intraperitoneal (IPI). A: Mean percentage of CD4+ thymocytes via IMI. B: Mean percentage of CD4+ thymocytes via IPI. C: Mean percentage of CD8+ thymocytes via IMI. D: Mean percentage of CD8+ thymocytes via IPI. The number of control and immunized mice per each group was 5 . Differences were considered significant when $P$ values were $<0.05$. The number of asterisks represents the degree of significance. $* P<0.05$, $* * P<0.005$, and $* * * P<0.0005$. ns: not significant

significant IM B-cell induction was obtained by the $\mathrm{N}$ alone, whereas most significant IP induction was obtained by the VN (Figure 4E and 4F).

\section{Discussion}

Successful outcome of vaccination can be influenced by vaccine formulation, type of adjuvant, and immunization route. While an immunization route for a given vaccine may induce protection against an infection, the same route may not lead to the desired protection against other infection [22, 23]. In fact, not only vaccine seeds but also adjuvants used in combination with vaccines are essential in achieving optimal protective immunity [24, 25]. 
A
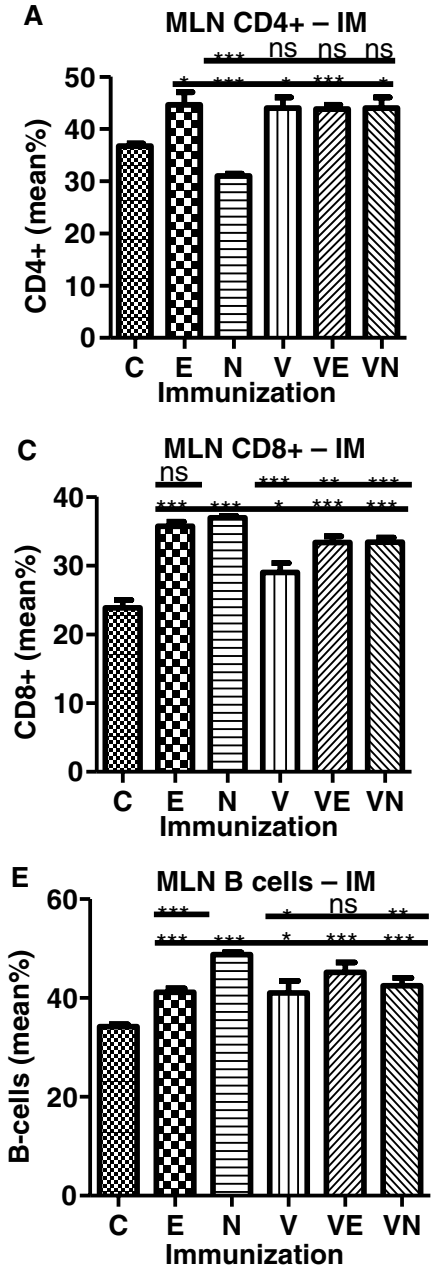
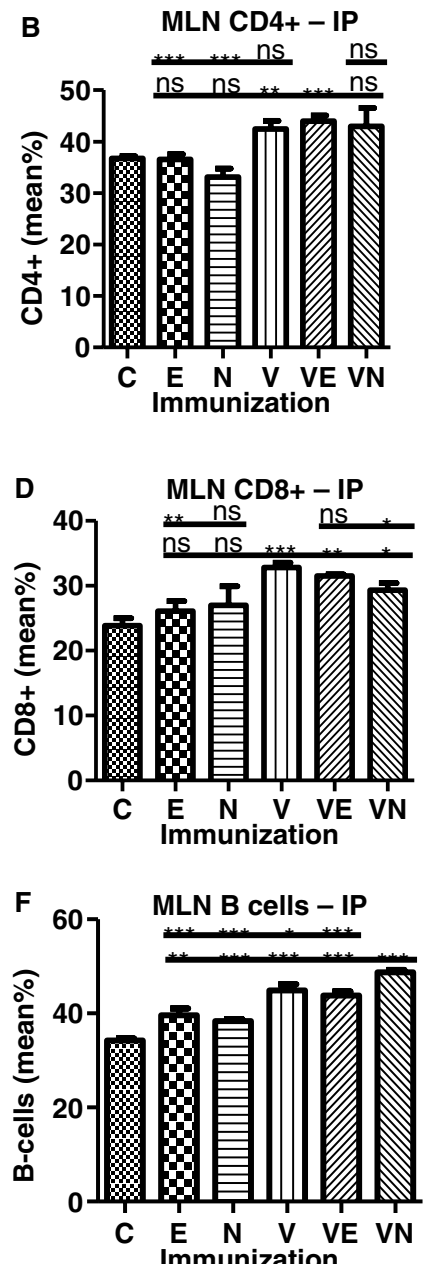

Figure 4. Mean percentage of CD4+, CD8+, and B-MLN lymphocytes at $4^{\text {th }}$ week of immunization from mice immunized by anti-HPAI vaccine (V) preparation supplementing with Echinacea purpurea (E) and Nigella sativa (N) via two routes of immunizations, i.e., intramuscular (IMI) or intraperitoneal (IPI). A: Mean percentage of CD4+ lymphocytes via IMI. B: Mean percentage of CD4+ lymphocytes via IPI. C: Mean percentage of CD8+ lymphocytes via IMI. D: Mean percentage of CD8+ lymphocytes via IPI. E: Mean percentage of B-lymphocytes via IMI. F: Mean percentage of B-lymphocytes via IPI. The number of control and immunized mice per each group was 5 .

Differences were considered significant when $P$ values were $<0.05$. The number of asterisks represents the degree of significance. $* P<0.05, * * P<0.005$, and $* * * P<0.0005$. ns: not significant 
Although poultry but not mouse represents the natural final host for avian influenza infection, several recent studied evaluated immunogenicity and protective capacity of anti-H5N1 avian influenza vaccines in mice [26-28]. In fact, most of the available vaccine strains against avian influenza including the one we used in the present work are generated by reverse genetics [14] on the background of the mouse adapted PR8-H1N1 strain [29] which makes mouse a relevant model for characterizing immune responses induced by such vaccines. Other convincing reasons for us to use mouse as an animal model in our experiments are feasibility of its maintenance, handling, and availability of immunological reagents for postvaccination studies of both humoral and cellular responses [30].

Induced humoral and cellular immune responses due to un-supplemented killed reassorted virus $(V)$

The induced IgM peaks both at $2^{\text {nd }}, 3^{\text {rd }}$, and $4^{\text {th }}$ WPIPI and IgG peaks both at $2^{\text {nd }}$ and $3^{\text {rd }}$ WPIMI by V reflect route-specific immune stimulation which agrees with Gao et al. [31] who demonstrated that IMI with whole inactivated human adenovirus particles was more protective than intranasal immunization. On contrary, although using a different vaccine and different routes of immunization, Ledgerwood et al. [32] found that changing route of immunization with a DNA vaccine encoding the HA molecule H5 from IMI to intradermal did not lead to a significant advantage in the immunological outcome.

In the same direction, our cellular results upon immunization with $\mathrm{V}$ showed the capacity of both IMI and IPI to induce proliferation of CD4+ but IMI only led to stimulate $\mathrm{CD} 8+$ thymocytes, while both routes induced significant increases in CD4+T, CD8+T, and B-MLN cells. Along the same lines and although using different strains and having different aims, in a study where aiming at inducing cross-protection against heterologous human influenza subtypes, Wang et al. [33] showed capacity of IMI but not IPI with live PR8-H1N1 to protect against a challenge infection with $\mathrm{H} 3 \mathrm{~N} 2$ although both routes equally stimulated CD8+ $\mathrm{T}$ cells which allows us to suggest that in their case-protective immunity is CD8+-independent. The authors attributed the privilege of the IMI above IPI to the proximity of the IMI to induce local immune responses in the draining lymph node unlike the uneasy stimulation of the distal lymphoid organs in case of IPI which is always accompanied by systemic dilution of the antigens.

E. purpurea and N. sativa ( $E$ and $N$ )

The phenomenon of the route-specific immune stimulation was also obvious. However, in case of both extracts, the IPI elicited better humoral immune 
responses than the IMI. Extracts of $\mathrm{E}$ and $\mathrm{N}$ were able to increase the titer of IgM and IgG in case of both routes (IMI and IPI) at the earliest time point of administration. We also showed that this response was inverted at $3^{\text {rd }}$ and $4^{\text {th }}$ WPIMI and WPIPI of injections. Controversial results were reported on the immunological effects of action of $\mathrm{E}$ where Rehman et al. [34] described the capacity of its extract to induce IgG production in rats and Mishima et al. [16] recorded the opposite. The inverted effect of the Echinacea extract on IgG production seen in our results was explained by Hayashi et al. [35] on the capacity of the same extract to suppress the humoral immune responses through stimulating IFN- $\gamma$ production.

The significant stimulation of MLN CD4+, CD8+, B cells, and CD8+ thymocytes due to IPI of $\mathrm{E}$ and CD4+ thymocytes due to IMI of E were in agreement with Redondo [17] who attributed the ability of $E$ to stimulate the immune system by enhancing both production of antibodies and T-cell responses, Bodinet and Freudenstein [15] who demonstrated the capacity of extracts from different parts of Echinacea sp. to activate neutrophils, macrophages, T cells, and B cells. The significant increases in MLN-B cells and CD8+ thymocytes induced by IPI with N were consistent with Salem and Hossain [18] who reported that $\mathrm{N}$ enhanced the cellular immunity and with Islam et al. [36] who found that some constituents of $\mathrm{N}$ exert a stimulatory effect toward T-cell-mediated immune responses. The antiviral effect of the $\mathrm{N}$ oil was reported by Salem and Hossain [18], Abuharfeil et al. [37] to be associated with enhancing $\mathrm{CD}^{+}$and $\mathrm{CD}^{+}$cell responses, and macrophages, and augmenting their ability to produce IFN- $\gamma$.

\section{Supplemented killed virus with E or N (VE and VN)}

The significant decreases seen in the levels of $\operatorname{IgM}$ at $3^{\text {rd }}$ and $4^{\text {th }}$ WPIMI or WPIPI with the supplemented vaccine by $\mathrm{E}$ compared with the $\mathrm{V}$ alone reflected a regulatory effect of the $\mathrm{E}$ on the induced IgM response by the $\mathrm{V}$. This could be partially explained to be due to denaturing some of the antigenic determinant of the $\mathrm{V}$ by the $\mathrm{E}$ [38-41]. It falls in agreement with a previous report on a possible immune suppressive effect by E [35].

The observed significant increase in the IgM upon IMI of mice with supplemented $\mathrm{V}$ with $\mathrm{N}$ in comparison with the treated animals with the unsupplemented $\mathrm{V}$ reveals an immunostimulatory effect of the $\mathrm{N}$. This can be due to a direct effect of the plant extract on the host immune response [18] or due to an indirect effect of the $\mathrm{N}$ that leads to chemical structural modification (epitope exposure) of the V [38-41]. Although IPI with VN still caused a significant 
increase in IgM levels compared with the control animals, interestingly, an opposite effect was seen, i.e., significantly less stimulation of IgM in case of treating mice with supplemented vaccine by $\mathrm{N}$ compared with $\mathrm{V}$ alone.

Since the levels of IgM both in case of the IMI and IPI with $\mathrm{V}$ alone were comparable, the drop in the IgM level upon supplementing the $\mathrm{V}$ by $\mathrm{N}$ in case of the IPI cannot be only interpreted to be due to changing the site of immunization but it rather opens a question of an additional unknown factor which modulates the exerted effect by $\mathrm{N}$ in either of the two site. This unknown factor makes the effect of $\mathrm{N}$ stimulatory in the case of IMI and regulatory in the case of IPI. The significant enhancement of the $\operatorname{IgG}$ response both at $4^{\text {th }}$ WPIMI, $2^{\text {nd }}$ and $3^{\text {rd }}$ WPIPI upon supplementing the $\mathrm{V}$ with $\mathrm{N}$ compared with the un-supplemented $\mathrm{B}$ further confirms the immunostimulatory effect of $\mathrm{N}$ at the humoral level.

The obvious increase in the counts of the CD4+ thymocytes in animals which received IMI by the supplemented vaccine with $\mathrm{E}$ compared with mice which received the un-supplemented $\mathrm{V}$ or the $\mathrm{E}$ separately via the same route further suggests the improvement of the antigenicity of the $\mathrm{V}$ by the $\mathrm{E}$ which can be attributed to induced structural changes. This agrees with previous reports on conformational changes induced in some vaccines due to treatment with adjuvants [38-41]. As for the CD8+ thymocytes, absence of significant differences between animals which received IMI with either $\mathrm{V}, \mathrm{VE}$, or $\mathrm{VN}$ and the obvious significant differences between their levels in the three animal groups compared with mice which received either $\mathrm{E}$ or $\mathrm{N}$ alone confirm that the induction is mainly due to the $\mathrm{V}$ antigens.

The significant drop in the level of CD4+ thymocytes seen in mice who received IPI with VE compared with mice immunized with $\mathrm{E}$ alone via the same route reflects the hindering effect of the $\mathrm{V}$ on the stimulatory effect of the $\mathrm{E}$ and the opposite was seen for CD8+ thymocytes which reflected that $\mathrm{E}$ enhanced the antigenicity of $\mathrm{V}$ [15]. The almost identical levels of CD4+ and CD8+ thymocytes in mice who received IPI with either $\mathrm{N}$ or VN and the significantly higher levels of such cells in both mice groups compared with animals who received the un-supplemented $\mathrm{V}$ suggest that the stimulatory effect is mainly due to $\mathrm{N}$ alone [18].

The absence of any significant differences between levels of MLN-CD4+ cells in mice treated via the IM route with either E or V or VE suggests that supplementing the vaccine with the $\mathrm{E}$ did not improve the immune outcome stimulated by either of them. Unlikely the immune stimulation of MLN-CD4+ cells in IM- or IP-treated mice with or VN was due to the V but not the $\mathrm{N}$ since levels of such cells were almost identical in mice treated with either V and VN, nevertheless, levels in both groups were significantly higher than in mice treated with $\mathrm{N}$ alone and the same holds true for IP-treated mice with VE and V. 
Our results showed that the stimulation of the MLN-CD8+ cells in case of the IMI was due to either $\mathrm{E}$ or $\mathrm{N}$ upon being combined with $\mathrm{V}$ and the opposite was seen for the same cell subset in case of IPI confirming route-specific response. Also, our IMI data clearly showed the enhancement of the MLN-B cells due to combining the $\mathrm{E}$ and $\mathrm{V}$ as it gave better response than either $\mathrm{E}$ or $\mathrm{V}$ separately which might be due to modification of the antigenicity of the $\mathrm{V}$ by the $\mathrm{E}$; however, the resulting stimulation of such cells with the $\mathrm{VN}$ was mainly due to $\mathrm{N}$ as both mouse groups showed comparable levels of the cells which was in either case significantly higher than that induced by the V. Last but not least, the enhanced MLN-B cells in case of IPI mice with the VN was due to combined effect of both components as it showed better stimulation than either $\mathrm{N}$ or $\mathrm{V}$; however, the obtained effect in case of VE was clearly due to the V.

\section{Conclusions}

Altogether, the study highlights the value of the present work to identify economic natural adjuvants which can induce non-specific immunity against circulating avian influenza viruses and increase efficacy of the used vaccines through either of the two used routes of immunization.

IM immunization with the supplemented reassorted killed virus by the $\mathrm{N}$ stimulated the humoral immune responses in comparison with the extract-free vaccine which highly suggests the immune stimulatory adjuvant effect of this plant extract.

The distinct differences in the trend of both the cellular and humoral responses resulting from the IPI and IMI by the supplemented, un-supplemented vaccine as well as the plant extracts alone clearly suggest route-specific immune modulation which was always privileged in case of IMI.

Last but not least, the capacity of the $\mathrm{E}$ to downregulate both the induced cellular and humoral responses by the $\mathrm{V}$ highlights the possible potential usefulness of such plant extract in supplementing vaccines prior to immunizing hyperimmune or autoimmune patients who are known to undergo severe inflammatory responses upon being vaccinated which sometimes can be fatal which goes beyond the original aim of this study.

\section{Acknowledgements}

The authors acknowledge the National Research Centre (NRC) of Egypt for providing all required facilities and logistics for the work. They would also like to highly thank Dr. Richard Webby, St. Jude Children's Research Hospital, 
Memphis, TN, USA for providing the plasmids used to generate the reassorted influenza virus. Mahmoud Mohamed Bahgat and Amany Sayed Maghraby contributed equally to the study.

\section{Conflict of Interest}

The authors declare no conflict of interest.

\section{References}

1. Webster, R. G., Govorkova, E. A.: Continuing challenges in influenza. Ann N Y Acad Sci 1323, 115-139 (2014).

2. Hobson, D., Curry, R. L., Beare, A. S., Ward-Gardner, A.: The role of serum haemagglutination-inhibiting antibody in protection against challenge infection with influenza A2 and B viruses. J Hyg (Lond) 70, 767-777 (1972).

3. Grodeland, G., Mjaaland, S., Roux, K. H., Fredriksen, A. B., Bogen, B.: DNA vaccine that targets hemagglutinin to MHC Class II: Molecules rapidly induces antibody-mediated protection against influenza. J Immunol 191, 3221-3231 (2013).

4. Strengell, M., Ikonen, N., Ziegler, T., Julkunen, I.: Minor changes in the hemagglutinin of influenza A (H1N1) 2009 virus alter its antigenic properties. PLoS One 6, e25848 (2011).

5. Kim, J. K., Kayali, G., Walker, D., Forrest, H. L., Ellebedy, A. H., Griffin, Y. S., Rubrum, A., Bahgat, M. M., Kutkat, M. A., Ali, M. A., Aldridge, J. R., Negovetich, N. J., Krauss, S., Webby, R. J., Webster, R. G.: Puzzling inefficiency of H5N1 influenza vaccines in Egyptian poultry. Proc Natl Acad Sci U S A 107, 11044-11049 (2010).

6. Das, K., Aramini, J. M., Ma, L. C., Krug, R. M., Arnold, E.: Structures of influenza A proteins and insights into antiviral drug targets. Nat Struct Mol Biol 17, 530-538 (2010).

7. Ge, H., Wang, Y. F., Xu, J., Gu, Q., Liu, H. B., Xiao, P. G., Zhou, J., Liu, Y., Yang, Z., Su, H.: Anti-influenza agents from Traditional Chinese Medicine. Nat Prod Rep 27, 1758-1780 (2010).

8. von Itzstein, M.: The war against influenza: Discovery and development of sialidase inhibitors. Nat Rev Drug Discov 6, 967-974 (2007).

9. Hayden, F. G., de Jong, M. D.: Emerging influenza antiviral resistance threats. J Infect Dis 203, 6-10 (2011).

10. Rimmelzwaan, G. F., Osterhaust, A. D.: Influenza vaccines: New developments. Curr Opin Pharmacol 1, 491-496 (2001).

11. Cooper, P. D., Petrovsky, N.: Delta inulin: A novel, immunologically active, stable packing structure comprising $\beta$-D-[2->1] poly(fructo-furanosyl) $\alpha$-D-glucose polymers. Glycobiology 21, 595-606 (2011).

12. Vesikari, T., Knuf, M., Wutzler, P., Karvonen, A., Kieninger-Baum, D., Schmitt, H. J., Baehner, F., Borkowski, A., Theodore, F. T., Clemens, R.: Oil-in-water emulsion adjuvant with influenza vaccine in young children. N Engl J Med 365, 1406-1416 (2011). 
13. Herzog, C., Hartmann, K., Künzi, V., Kürsteiner, O., Mischler, R., Lazar, H., Glück, R.: Eleven years of Inflexal ${ }^{\circledR} \mathrm{V}-\mathrm{A}$ virosomal adjuvanted influenza vaccine. Vaccine 27, 4381-4387 (2009).

14. Hoffmann, E., Krauss, S., Perez, D., Webby, R., Webster, R. G.: Eight-plasmid system for rapid generation of influenza virus vaccines. Vaccine 20, 3165-3170 (2002).

15. Bodinet, C., Freudenstein, J.: Effects of an orally applied aqueous-ethanolic extract of a mixture of Thujae occidentalis herba, Baptisiae tinctoriae radix, Echinacea purpurea radix and Echinacea pallidae radix on antibody response against sheep red blood cells in mice. Planta Med 65, 695-699 (1999).

16. Mishima, S., Saito, K., Maruyama, H., Inoue, M., Yamashita, T., Ishida, T., Yeunhwa, G. U.: Antioxidant and immunoenhancing effects of Echinacea purpurea. Biol Pharm Bull 27, 1004-1009 (2004).

17. Redondo, L.: La Equinácea purpúrea: una alternativa real para estimular el sistema inmunológico. Rev Fitoterapia 1, 15-24 (2000).

18. Salem, M. L., Hossain, M. S.: Protective effect of black seed oil from Nigella sativa against murine cytomegalovirus infection. Int J Immunopharmacol 22, 729-740 (2000).

19. Assayed, M. E.: Radioprotective effects of black seed (Nigella sativa) oil against hemopoietic damage and immunosuppression in gamma-irradiated rats. Immunopharmacol Immunotoxicol 32, 284-296 (2010).

20. Bahgat, M. M., Kutkat, M. A., Nasraa, M. H., Mostafa, A., Webby, R., Bahgat, I. M., Ali, M. A.: Characterization of an avian influenza virus H5N1 Egyptian isolate. J Virol Methods 159, 244-250 (2009).

21. Maghraby, A., Bahgat, M.: Immunostimulatory effect of coumarin derivatives before and after infection of mice with the parasite Schistosoma mansoni. Arzneimittelforschung 54, 545-550 (2004).

22. Hu, H., Lu, X., Tao, L., Bai, B., Zhang, Z., Chen, Y.: Induction of specific immune responses by severe acute respiratory syndrome corona virus spike DNA vaccine with or without interleukin-2 immunization using different vaccination routes in mice. Clin Vaccine Immunol 14, 894-901 (2007).

23. Hu, H., Huang, X., Tao, L., Huang, Y., Cui, B. A., Wang, H.: Comparative analysis of the immunogenicity of SARS-CoV nucleocapsid DNA vaccine administrated with different routes in mouse model. Vaccine 27, 1758-1763 (2009).

24. Halman, C.: New approaches to vaccine delivery. In Hannoun, C., Kendal, A. P., Klenk, H. D., Ruben, F. L. (eds): Options for the Control of Influenza, Volume II. Excerpta Medica, Amsterdam, The Netherlands, 1993, pp. 389-391.

25. Palese, P.: Making better influenza virus vaccines? Emerg Infect Dis 12, 61-65 (2006).

26. Zhang, J., Fan, H. Y., Zhang, Z., Zhang, J., Zhang, J., Huang, J. N., Ye, Y., Liao, M.: Recombinant baculovirus vaccine containing multiple M2e and adjuvant LTB induces T cell dependent, cross-clade protection against H5N1 influenza virus in mice. Vaccine 27, 622-629 (2016).

27. Cox, F., Baart, M., Huizingh, J., Tolboom, J., Dekking, L., Goudsmit, J., Saeland, E., Radošević, K.: Protection against H5N1 influenza virus induced by matrix-M adjuvanted seasonal virosomal vaccine in mice requires both antibodies and T cells. PLoS One 10, e0145243 (2015). 
28. Kim, I. H., Kwon, H. J., Park, J. K., Song, C. S., Kim, J. H.: Optimal attenuation of a PR8-derived mouse pathogenic H5N1 recombinant virus for testing antigenicity and protective efficacy in mice. Vaccine 17, 6314-6319 (2015).

29. Blazejewska, P., Koscinski, L., Viegas, N., Anhlan, D., Ludwig, S., Schughart, K.: Pathogenicity of different PR8 influenza A virus variants in mice is determined by both viral and host factors. Virology 412, 36-45 (2010).

30. Margine, I., Krammer, F.: Animal model for influenza viruses: Implications for universal vaccine development. Pathogens 3, 845-874 (2014).

31. Gao, W., Soloff, A. C., Lu, X., Montecalvo, A., Nguyen, D. C., Matsuoka, Y., Robbins, P. D., Swayne, D. E., Donis, R. O., Katz, J. M., Barratt-Boyes, S. M., Gambotto, A.: Protection of mice and poultry from lethal $\mathrm{H} 5 \mathrm{~N} 1$ avian influenza virus through adenovirusbased immunization. J Virol 80, 1959-1964 (2006).

32. Ledgerwood, J. E., Hu, Z., Gordon, I. J., Yamshchikov, G., Enama, M. E., Plummer, S., Bailer, R., Pearce, M. B., Tumpey, T. M., Koup, R. A., Mascola, J. R., Nabel, G. J., Graham, B. S.: Influenza virus H5 DNA vaccination is immunogenic by intramuscular and intradermal routes in humans. Clin Vaccine Immunol 19, 1792-1797 (2012).

33. Wang, Z. F., Chua, B. Y., Ramos, J. V., Qui, S. M., Parra, N., Fairmaid, E., Brown, E. L., Jackson, D. C., Kedzierska, K.: Establishment of functional influenza virus-specific CD8+ $\mathrm{T}$ cell memory pools after intramuscular immunization. Vaccine 33, 5148-5154 (2015).

34. Rehman, J., Dillow, J. M., Carter, S. M., Chou, J., Le, B., Maisel, A. S.: Increased production of antigen specific immunoglobulins $\mathrm{G}$ and $\mathrm{M}$ following in vivo treatment with the medicinal plants Echinacea angustifolia and Hydrastis canadensis. Immunol Lett $\mathbf{6 8}$, 391-395 (1999).

35. Hayashi, I., Ohotsuki, M., Suzuki, I., Watanabe, T.: Effects of oral administration of Echinacea purpurea (American herb) on incidence of spontaneous leukemia caused by recombinant leukemia viruses in AKR/J mice. J Clin Immunol 24, 10-20 (2001).

36. Islam, S. N., Begum, P., Ahsan, T., Huque, S., Ahsan, M.: Immunosuppressive and cytotoxic properties of Nigella sativa. Phytother Res 18, 395-398 (2004).

37. Abuharfeil, N. M., Salim, M., Von Kleist, S.: Augmentation of natural killer cell activity in vivo against tumor cells by some wild plants from Jordan. Phytother Res 15, 109-113 (2001).

38. Wang, Y. Q., Wu, J., Fan, Q. Z., Zhou, M., Yue, Z. G., Ma, G. H., Su, Z. G.: Novel vaccine delivery system induces robust humoral and cellular immune responses based on multiple mechanisms. Adv Health Mater 3, 670-681 (2014).

39. Lei, H., Peng, X., Ouyang, J., Zhao, D., Jiao, H., Shu, H., Ge, X.: Intranasal immunization of recombinant Lactococcus lactis induces protection against H5N1 virus in ferrets. Virus Res 196, 56-59 (2015).

40. Xu, W., Zheng, M., Zhou, F., Chen, Z.: Long-term immunogenicity of an inactivated split-virion 2009 pandemic influenza A H1N1 virus vaccine with or without aluminum adjuvant in mice. Clin Vaccine Immunol 22, 327-335 (2015).

41. Song, L., Xiong, D., Hu, M., Kang, X., Zhiming, P., Jiao, X.: Immunopotentiation of different adjuvants on humoral and cellular immune responses induced by HA1-2 subunit vaccines of H7N9 influenza in mice. PLoS One 11, e0150678 (2016). 